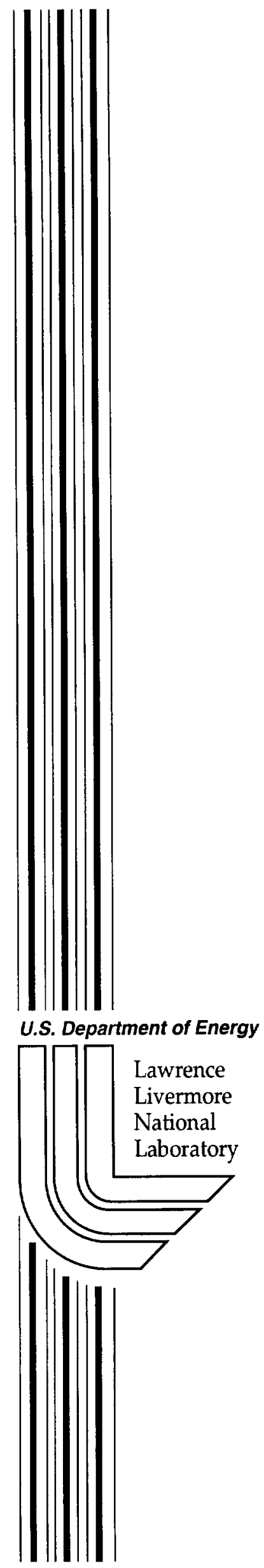

\title{
Evaluation of MOSFETS and IGBTS for Pulsed Power Applications
}

\author{
B. Hickman, E. Cook
}

This article was submitted to 2001 The Institute of Electrical and Electronics Engineers, Inc. Pulsed Power Plasma Science Conference, Las Vegas, NV, June $17-22,2001$

\section{May 31, 2001}




\section{DISCLAIMER}

This document was prepared as an account of work sponsored by an agency of the United States Government. Neither the United States Government nor the University of California nor any of their employees, makes any warranty, express or implied, or assumes any legal liability or responsibility for the accuracy, completeness, or usefulness of any information, apparatus, product, or process disclosed, or represents that its use would not infringe privately owned rights. Reference herein to any specific commercial product, process, or service by trade name, trademark, manufacturer, or otherwise, does not necessarily constitute or imply its endorsement, recommendation, or favoring by the United States Government or the University of California. The views and opinions of authors expressed herein do not necessarily state or reflect those of the United States Government or the University of California, and shall not be used for advertising or product endorsement purposes.

This is a preprint of a paper intended for publication in a journal or proceedings. Since changes may be made before publication, this preprint is made available with the understanding that it will not be cited or reproduced without the permission of the author.

This work was performed under the auspices of the United States Department of Energy by the University of California, Lawrence Livermore National Laboratory under contract No. W-7405-Eng-48.

This report has been reproduced directly from the best available copy.

Available electronically at http://www.doc.gov/bridge

Available for a processing fee to U.S. Department of Energy And its contractors in paper from

U.S. Department of Energy

Office of Scientific and Technical Information

P.O. Box 62

Oak Ridge, TN 37831-0062

Telephone: (865) 576-8401

Facsimile: (865) 576-5728

E-mail: reports@adonis.osti.gov

Available for the sale to the public from

U.S. Department of Commerce

National Technical Information Service

5285 Port Royal Road

Springfield, VA 22161

Telephone: (800) 553-6847

Facsimile: (703) 605-6900

E-mail: orders@ntis.fedworld.gov

Online ordering: http://www.ntis.gov/ordering.htm

OR

Lawrence Livermore National Laboratory

Technical Information Department's Digital Library

http://www.llnl.gov/tid/Library.html 


\title{
EVALUATION OF MOSFETS AND IGBTS FOR PULSED POWER APPLICATIONS*
}

\author{
B. Hickman, E. Cook \\ Lawrence Livermore National Laboratory \\ 7000 East Ave. Livermore, CA 94550 \\ Mail Stop L-645
}

\section{Abstract}

Single solid-state devices or arrays of solid-state devices are being incorporated into many pulsed power applications as a means of generating fast, high-power, high repetition-rate pulses and ultimately replacing hard tubes and thyratrons. While vendors' data sheets provide a starting point for selecting solid-state devices, most data sheets do not have sufficient information to determine performance in a pulsed application. To obtain this relevant information, MOSFET's and IGBT's from a number of vendors have been tested to determine rise times, fall times and current handling capabilities. The emphasis is on the evaluation of devices that can perform in the range of $100 \mathrm{~ns}$ pulse widths and the test devices must be capable of switching 1000 volts or greater at a pulsed current of at least 25 amperes. Additionally, some devices were retest with a series magnetic switch to evaluate the effects on switching parameters and specifically rise times. All devices were evaluated under identical conditions and the complete test results are presented.

\section{INTRODUCTION}

The Beam Research program at Lawrence Livermore National Laboratory has been developing solid-state high voltage adders for induction accelerator applications. The biggest determining factor of the performance of these adders is the series/parallel array of field effect transistors (MOSFETs) and/or insulated gate bipolar transistors (IGBTs) used for the main switching device. Once the parameters are determined for the adder (voltage, current, pulse width, rise and fall times, mechanical constraints, etc.) a device can be chosen that best fits the application. Since the vendors' data sheets for these devices do not always provide sufficient performance information for the narrow pulse widths required ( $100 \mathrm{~ns})$, the selection process for the optimum device becomes a significant research and testing effort in itself. Samples of MOSFETs and IGBTs received from multiple vendors, such as APT, IXYS, and Intersil, are tested for their performance. The data for all devices are compiled and compared and a candidate that best meets the optimal parameters is chosen. This paper describes the test setup, procedures and results for devices that have a rating of 1000 volts or greater for a pulsed current of at least 25 amperes.

\section{TEST SET-UP}

When testing devices for rise and fall times, the total loop inductance in the circuit/test fixture significantly affects the device turn-on time and to determine the true speed of the device, the inductance of the circuit/fixture needs to be as low as physically possible. In order to achieve this a test fixture was designed and fabricated for the specific purpose of testing these devices. Traces on the pc boards were made very wide and kept as close to one another as possible. Also, the capacitor bank was made up of several capacitors in parallel. The load boards were also made with wide, close traces and many resistors in parallel.

The test circuit has a capacitor bank with enough stored energy to sustain a desired pulse width without excessive droop for a wide range of load currents. The test circuit also has interchangeable resistive loads so the current through the device can be varied.

The gate drive circuit used in this test fixture was developed for a previous application and was designed specifically to turn these devices on and off very quickly. It is tightly coupled to the test device to minimize inductance.

MOSFETs and IGBTs come in a variety of case sizes and the ones that best fit our application are the TO-247 and TO-264 packages. The test fixture was designed to accommodate either. Figure 1. shows the test circuit.

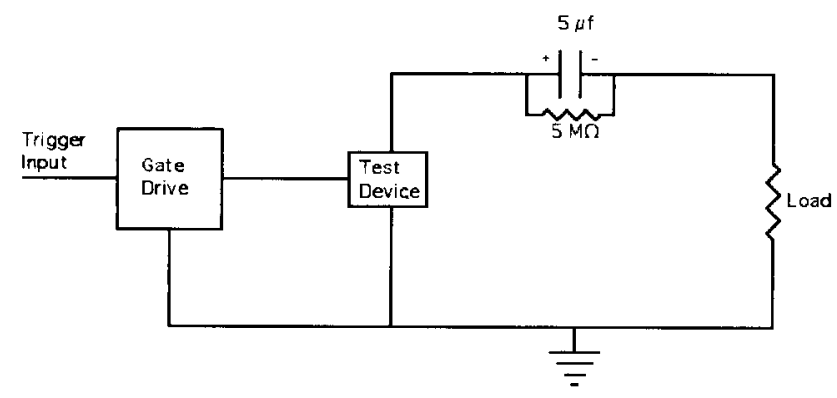

Figure 1. Test circuit

*This work performed under the auspices of the U.S. Department of Energy by the University of California, Lawrence Livermore National Laboratory under Contract No. W-7405-Eng-48 


\section{INITIAL CIRCUIT TESTING}

The first device tested in the fixture was an APT 1001RBVR $(1000 \mathrm{~V}, 10 \mathrm{~A})$ MOSFET that was used in other applications and had been well characterized. Preliminary testing was at 600 volts into a $34 \Omega(17.65 \mathrm{~A})$ load with a $100 \mathrm{~ns}$ pulse width.

The testing of the circuit showed the fixture to be functioning properly but the turn-off time (26ns) of the test device (Figure 2.) was slightly slower than the $17 \mathrm{~ns}$ that had been documented for this device in other applications.

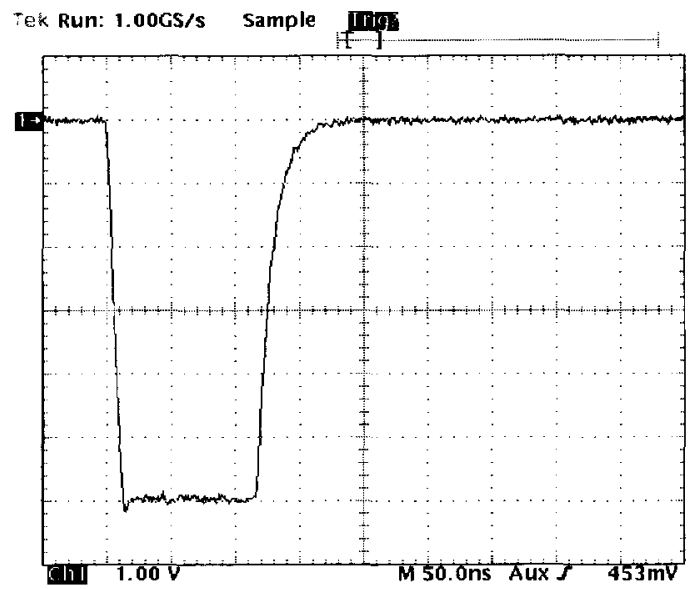

Figure 2. Load voltage for APT1001RBVR (600 volts, $34 \Omega, 100 \mathrm{~ns})$. Note: Since this is a negative pulse the oscilloscope measures the turn-on time as the "fall ".

\section{MODIFYING THE CIRCUIT}

Experiments showed that adding inductance to the circuit in parallel with the load resistor (Figure 4.) helped to speed up the turn-off time. It was decided to add the amount of inductance to the fixture that the device would normally see in the real application of an adder modulator (i.e. the magnetization current of the adder transformer primary winding). Measurements made on our existing adder showed each device would see approximately $33 \mu \mathrm{h}$ of inductance. A $33 \mu \mathrm{h}$ air core toroid was wound and added to the fixture and the load voltage was measured. Notice in Figure 3. the modification has decreased the turn-off time to $17 \mathrm{~ns}$ but there is now an inductive overshoot at the end of the pulse. This overshoot adds to the voltage already appearing across the device. Also, for fast repetition pulses, such as a burst mode, the voltage should return to zero volts before the device turns on again for the next pulse.

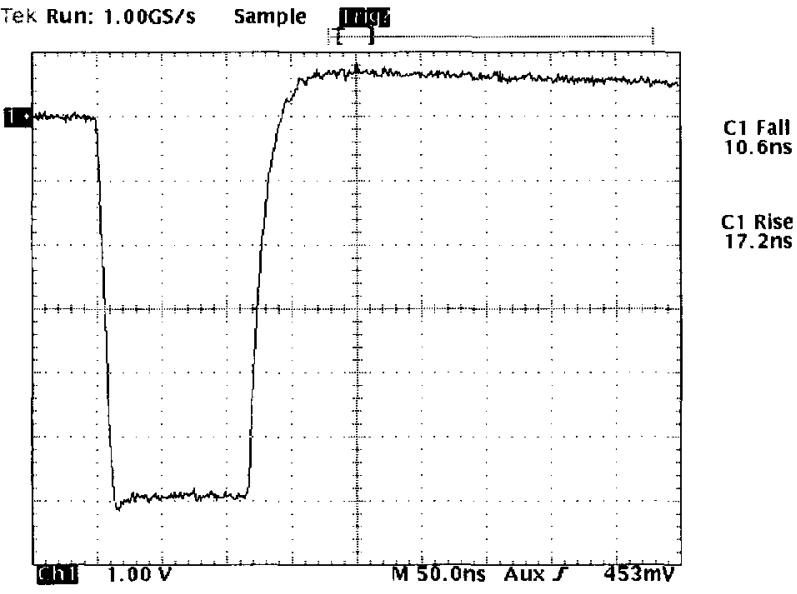

Figure 3. Load voltage with $33 \mu \mathrm{h}$ inductor.

A snubber circuit was added to the fixture to clamp this overshoot while maintaining the fast turn-off. With these circuit modifications the test fixture is a very close representation of a modulator type environment. Figure 4. shows the modified circuit.

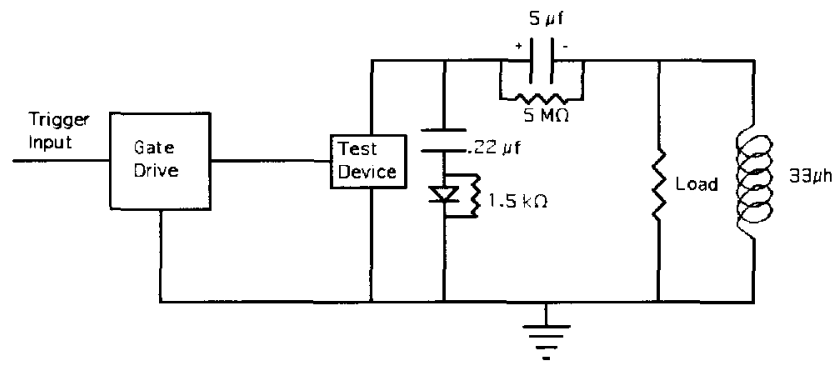

Figure 4. Modified circuit of test fixture.

Figure 5. shows the load voltage of the modified circuit. Notice there is very little overshoot and the turn-off time was slowed only slightly.

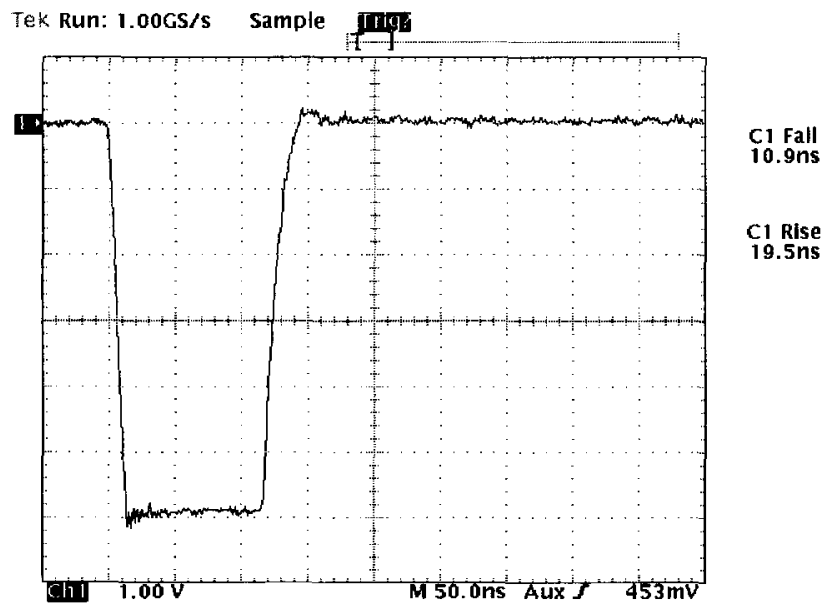

Figure 5. Load voltage with $33 \mu \mathrm{h}$ inductor and snubber added to the circuit. 


\section{TEST PROCEDURE}

In order to compare the performance of many devices the testing procedure and parameters were kept consistent throughout the experiment. The capacitor bank was charged to 1000 volts and the trigger input to the gate drive was set for a $100 \mathrm{~ns}$ pulse width. The load voltage was measured with a 100:1 voltage probe and the rise and fall times (10\%-90\%) were calculated by the oscilloscope. This data was recorded for each load value: $34 \Omega, 25.5 \Omega$, $20.3 \Omega, 16.8 \Omega, 14.7 \Omega, 12.5 \Omega, 10.2 \Omega, 8.5 \Omega, 5.7 \Omega, 2.7 \Omega$. As the current increased, the voltage drop across the device increased. The current through the device was calculated by measuring the load voltage and dividing it by the value of load resistance. Typical measurements at $1000 \mathrm{~V}$ on the DC capacitor are shown in Figure 6. Note the variation in voltage drop across the test device and also the effect on the rise and fall times. For the data collected here the "peak measured current" was arbitrarily chosen to be the current through the device when a 50 volt drop is measured across the device. Most of the IGBTs were too slow to be properly tested at $100 \mathrm{~ns}$ pulse widths and were retest with pulse widths of $500 \mathrm{~ns}$ or greater.

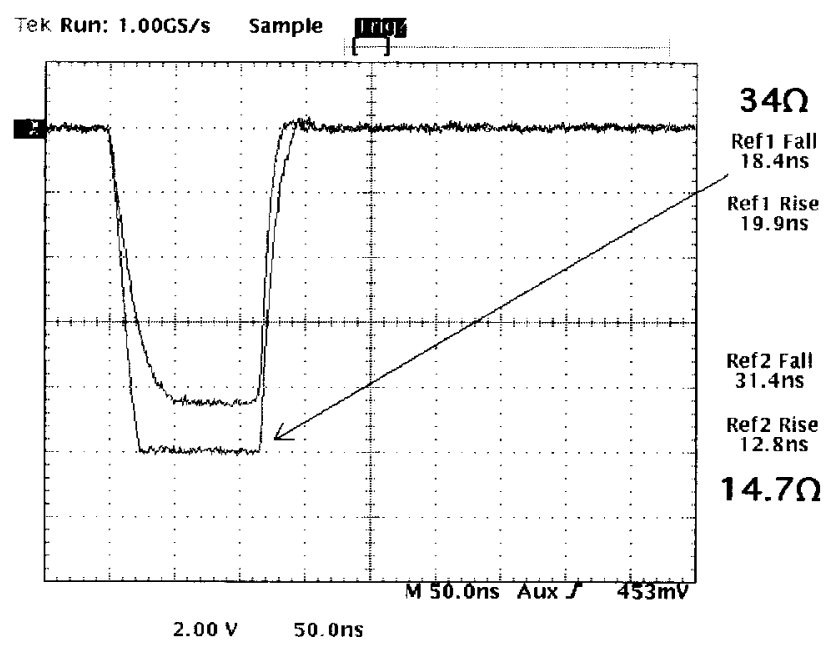

Figure 6. Overlay of $34 \Omega$ and $14.7 \Omega$ loads.

Once the voltage, current and rise and fall times of the device were recorded for each load value the next device was installed in the fixture and tested using the same exact conditions and procedures.

\section{TEST RESULTS}

The data for all devices was compiled (Table 1.) and performances compared.

Table 1. Performance of tested devices.

\begin{tabular}{|c|c|c|c|c|c|c|}
\hline Device & $\begin{array}{c}\text { Rated } \\
\text { Voltage }\end{array}$ & $\begin{array}{c}\text { Rated Pulsed } \\
\text { Current }\end{array}$ & $\begin{array}{c}\text { Peak Measured } \\
\text { Current }\end{array}$ & Turn-On Time & Turn-Off Time & Type \\
\hline APT1001RBLC & $1000 \mathrm{~V}$ & $44 \mathrm{~A}$ & $44 \mathrm{~A}$ & $19 \mathrm{~ns}$ & $13 \mathrm{~ns}$ & MOSFET \\
\hline APT1001RBVR & $1000 \mathrm{~V}$ & $44 \mathrm{~A}$ & $47 \mathrm{~A}$ & $20 \mathrm{~ns}$ & $13 \mathrm{~ns}$ & MOSFET \\
\hline APT10086BLC & $1000 \mathrm{~V}$ & $52 \mathrm{~A}$ & $56 \mathrm{~A}$ & $25 \mathrm{~ns}$ & $12 \mathrm{~ns}$ & MOSFET \\
\hline APT10050LVR & $1000 \mathrm{~V}$ & $84 \mathrm{~A}$ & $76 \mathrm{~A}$ & $34 \mathrm{~ns}$ & $13 \mathrm{~ns}$ & MOSFET \\
\hline APT10053LNR & $1000 \mathrm{~V}$ & $80 \mathrm{~A}$ & $85 \mathrm{~A}$ & $43 \mathrm{~ns}$ & $43 \mathrm{~ns}$ & MOSFET \\
\hline APT10040LVR & $1000 \mathrm{~V}$ & $100 \mathrm{~A}$ & $95 \mathrm{~A}$ & $44 \mathrm{~ns}$ & $40 \mathrm{~ns}$ & MOSFET \\
\hline APT1201R5BVR & $1200 \mathrm{~V}$ & $40 \mathrm{~A}$ & $40 \mathrm{~A}$ & $19 \mathrm{~ns}$ & $13 \mathrm{~ns}$ & MOSFET \\
\hline APT12080LVR & $1200 \mathrm{~V}$ & $64 \mathrm{~A}$ & $65 \mathrm{~A}$ & $26 \mathrm{~ns}$ & $12 \mathrm{~ns}$ & MOSFET \\
\hline HGTG27N120BN & $1200 \mathrm{~V}$ & $216 \mathrm{~A}$ & $56 \mathrm{~A}$ & $80 \mathrm{~ns}$ & $20 \mathrm{~ns}$ & IGBT \\
\hline IXBH40N160 & $1600 \mathrm{~V}$ & $40 \mathrm{~A}$ & $37 \mathrm{~A}$ & $60 \mathrm{~ns}$ & $20 \mathrm{~ns}$ & IGBT \\
\hline${ }^{* I X G H 45 N 120 ~}$ & $1200 \mathrm{~V}$ & $180 \mathrm{~A}$ & $361 \mathrm{~A}$ & $226 \mathrm{~ns}$ & $68 \mathrm{~ns}$ & IGBT \\
\hline${ }^{*}$ IXSH35N120A & $1200 \mathrm{~V}$ & $140 \mathrm{~A}$ & $172 \mathrm{~A}$ & $234 \mathrm{~ns}$ & $52 \mathrm{~ns}$ & IGBT \\
\hline${ }^{*}$ APT50GF120B2R & $1200 \mathrm{~V}$ & $160 \mathrm{~A}$ & $167 \mathrm{~A}$ & $415 \mathrm{~ns}$ & $90 \mathrm{~ns}$ & IGBT \\
\hline${ }^{*}$ APT20GF120BDR & $1200 \mathrm{~V}$ & $64 \mathrm{~A}$ & $60 \mathrm{~A}$ & $132 \mathrm{~ns}$ & $23 \mathrm{~ns}$ & IGBT \\
\hline${ }^{*}$ IXSH35N140A & $1400 \mathrm{~V}$ & $140 \mathrm{~A}$ & $173 \mathrm{~A}$ & $217 \mathrm{~ns}$ & $257 \mathrm{~ns}$ & IGBT \\
\hline${ }^{*}$ APT15GF170BDR & $1700 \mathrm{~V}$ & $50 \mathrm{~A}$ & $48 \mathrm{~A}$ & $12 \mathrm{~ns}$ & $19 \mathrm{~ns}$ & IGBT \\
\hline${ }^{*}$ IXBH42N170 & $1700 \mathrm{~V}$ & $180 \mathrm{~A}$ & $169 \mathrm{~A}$ & $133 \mathrm{~ns}$ & $61 \mathrm{~ns}$ & IGBT \\
\hline
\end{tabular}

* Tested at 500ns or greater pulse widths to obtain peak current. 


\section{MAGNETIC SWITCH ASSIST}

Several of the IGBTs that were tested had turn-on times that were too slow for our application. In an attempt to speed up these devices a magnetic switch was installed in series with the load (Figure 7).

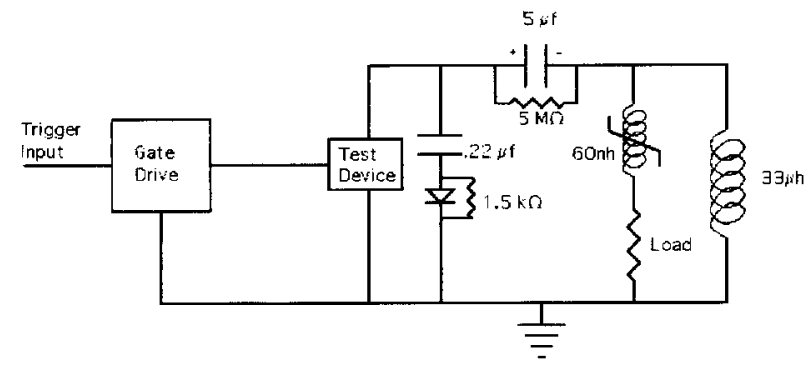

Figure 7. Circuit with magnetic switch.

The magnetic switch delays the current through the test device, giving the device time to fully turn on before conducting. Although the same magnetic switch was used for all of the devices and not optimized for each, it did have a substantial effect on the turn-on times for several of them. Figure 8. shows the load voltage for an IGBT (HGTG27N120BN) with and without magnetic switch assist. This device had a turn-on time that was too slow to reach it's peak current in $100 \mathrm{~ns}$. Therefore, it was tested at a 500ns pule width and reached a peak current of $98 \mathrm{~A}$. Table 2. shows turn-on times for several IGBTs that were improved using magnetic switch assist.

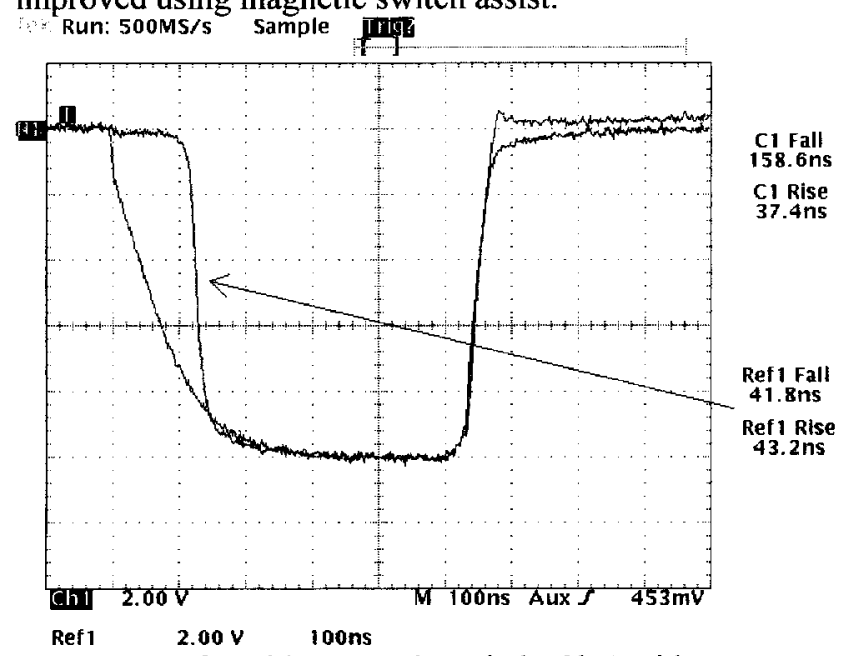

Figure 8. Ref 1 with magnetic switch, Ch 1 without.

Table 2. Turn-on times with and without magnetic switch

\begin{tabular}{|c|c|c|c|}
\hline Device & With & Without & Current \\
\hline IXBH40N160 & $43 \mathrm{~ns}$ & $60 \mathrm{~ns}$ & $38 \mathrm{~A}$ \\
\hline APT15GF170BR & $57 \mathrm{~ns}$ & $121 \mathrm{~ns}$ & $48 \mathrm{~A}$ \\
\hline APT20GF120BDR & $40 \mathrm{~ns}$ & $132 \mathrm{~ns}$ & $68 \mathrm{~A}$ \\
\hline HGTG27N120BN & $41 \mathrm{~ns}$ & $158 \mathrm{~ns}$ & $98 \mathrm{~A}$ \\
\hline APT50GF120B2R & $43 \mathrm{~ns}$ & $285 \mathrm{~ns}$ & $150 \mathrm{~A}$ \\
\hline
\end{tabular}

\section{SUMMARY}

Many MOSFETs and IGBTs were obtained from several vendors and tested for their performance in narrow pulse width conditions for the purpose of selecting a device that would best meet the strict parameters of a pulse power application. A circuit was designed and a low inductance test fixture was fabricated for this specific test effort. Voltage, current, turn-on times and turn-off times were recorded for each test device and the data was compiled and compared.

The MOSFETs typically had faster rise and fall times but were lower current devices than the IGBTs. Although the IGBTs met the current handling parameters for our application their rise and fall times were much too slow. Many of them had their turn-on times greatly improved using a magnetic switch in series with the load. Although this helped with many (not all) of the IGBTs, the magnetic switch did not improve the turn-on times of the MOSFETs. In fact some MOSFETs had their turn-on performances slowed by the added inductance of the magnetic switch.

\section{REFERENCES}

[1] E. G. Cook, "Inductive-Adder Kicker Modulator for DARHT-2", PPPS-2001, IEEE International Conference, June 17-22, 2001, Las Vegas, NV

[2] H. Kirbie, et al, "MHz Repetition Rate Solid-State Driver for High Current Induction Accelerators", 1999 Particle Accelerator Conference, New York, NY, March 29-April 2, 1999, http://ftp.pac99.bnl.gov/Papers/

[3] B. Lee, internal communications for gate drive circuit, LLNL, Livermore, CA 